ISSN 2236-0859

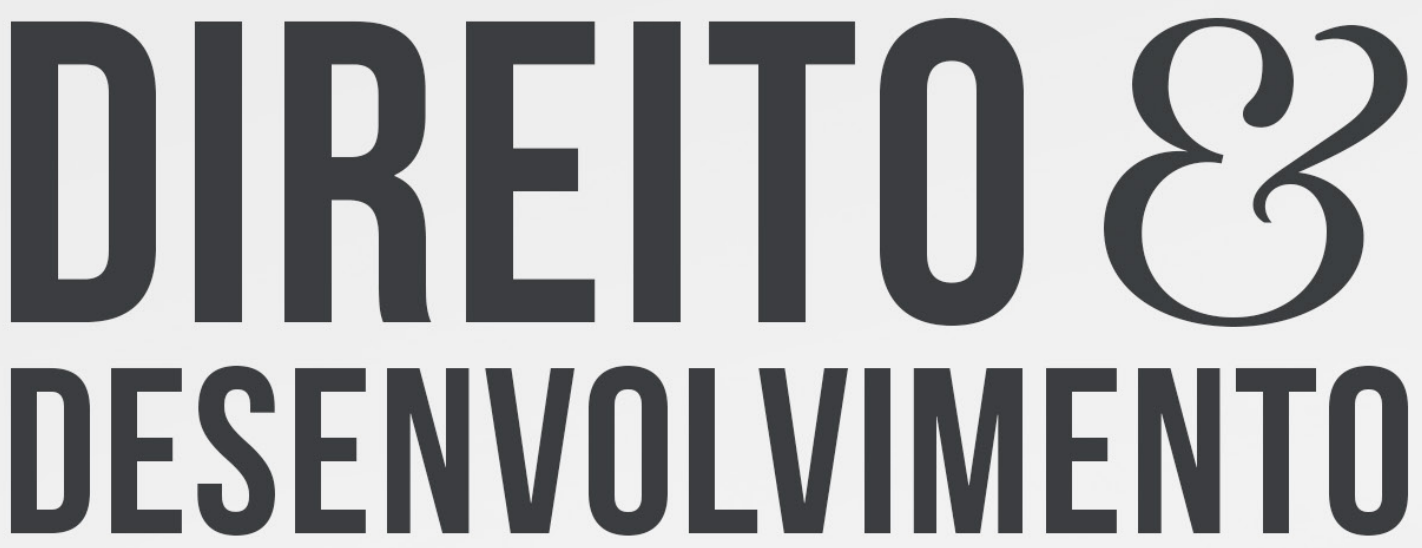

REVISTA DO PROGRAMA DE PÓS-GRADUAÇÃO EM DIREITO MESTRADO EM DIREITO E DESENVOLVIMENTO SUSTENTÁVEL

DOS PRESSUPOSTOS DE VALIDADE PARA A PRORROGACẼO POR INTERESSE PÚBLICODAS CONCESSÕES DE SERVICOO PÚBLICO

FELIPE MONTENEGRO VIVIANI GUIMARÃES

ODONE SANGUINÉ 


\title{
DOS PRESSUPOSTOS DE VALIDADE PARA A PRORROGAÇÃO POR INTERESSE PÚBLICO DAS CONCESSÕES DE SERVIÇO PÚBLICO
}

\section{THE VALIDITY PRESUPPOSITIONS FOR THE PUBLIC INTEREST PROROGATION OF PUBLIC SERVICE CONCESSIONS}

Recebido: 04/10/2019

Felipe Montenegro Viviani Guimarães ${ }^{1}$

Aprovado: 12/12/2019

Odone Sanguiné2

\section{RESUMO:}

Este artigo trata da prorrogação das concessões de serviço público por meras razões de conveniência e oportunidade das partes (ou prorrogação por interesse público). Seu objetivo é verificar os pressupostos de validade para a realização dessa espécie de prorrogação. O método de abordagem do tema é o dedutivo, e o método de pesquisa, o bibliográfico. Por fim, a principal conclusão deste artigo é que os pressupostos de validade da prorrogação por interesse público são: (i) previsão em lei; (ii) outorga precedida de licitação; (iii) previsão no edital de licitação; (iv) concessão em vigor; (v) não realização de prorrogação por interesse público anteriormente; (vi) fiel cumprimento do contrato pela concessionária; (vii) vantajosidade da medida; (viii) consenso entre as partes; e (ix) qualificação no Programa de Parcerias de Investimentos - PPI.

Palavras-chave: Direito Administrativo. Serviço público. Concessão. Prorrogação. Pressupostos de validade.

\begin{abstract}
:
This article deals with the prorogation of public service concessions for mere reasons of convenience and opportunity of the parties (or public interest prorogation). Its purpose is to verify the validity presuppositions for the realization of this species of prorogation. The method of approach of the theme is the deductive, and the research method, the bibliographic. Finally, the main conclusion of this article is that the validity presuppositions of the public interest prorogation are: (i) provision in law; (ii) grant preceded by public bidding; (iii) provision in the bid notice; (iv) concession in force; (v) non realization of public interest prorogation previously; (vi) faithful fulfillment of the concession contract by the concessionaire; (vii) advantage of the measure; (viii) agreement between the parties; and (ix) qualification in the Investment Partnership Program - PPI.
\end{abstract}

\footnotetext{
1 Doutorando e Mestre em Direito Administrativo pela Pontifícia Universidade Católica - SP. Advogado. Email: felipemvg@hotmail. com

2 Doutor pela Universitat Autònoma de Barcelona, Espanha. Pós-doutorado pela Washington University School of Law in St. Louis (MO), EUA e Universiteit Utrecht, Holanda. Professor Associado, classe D, nível o4, da Faculdade de Direito da UFRGS. Coordenador da Especialização em Direito Penal e Política Criminal: sistema constitucional e Direitos Humanos da UFRGS. Advogado. Desembargador aposentado do Tribunal de Justiça do Estado do Rio Grande do Sul (TJRS). Email: odonesang@hotmail. com
} 
Keywords:Administrativelaw. Publicservice. Concession. Prorogation. Validitypresuppositions.

\section{INTRODUÇÃO}

No presente artigo, nós analisaremos o instituto jurídico da prorrogação das concessões de serviço público, mais especificamente a prorrogação por meras razões de conveniência e oportunidade das partes ou, simplesmente, prorrogação por interesse público.

A referida análise justifica-se por diversas razões. Em primeiro lugar, porque a prorrogação por interesse público de inúmeras concessões foi autorizada, recentemente, no Brasil, por diversos atos normativos, de modo que o interesse teórico e prático pelo tema realmente é muito grande neste momento em nosso País ${ }^{3}$. Em segundo lugar, porque a prorrogação por interesse público constitui questão de monta, que afeta a vida de milhares de usuários, em geral por muitos anos, merecendo, pois, estudo acurado. E, em terceiro lugar, porque existem poucos artigos tratando, especificamente, da prorrogação por interesse público das concessões de serviço público, razão pela qual o presente trabalho buscará contribuir para o aprofundamento dos conhecimentos científicos sobre esse instituto do Direito Administrativo.

Assim sendo, nosso objetivo consiste em verificar os pressupostos de validade para a realização da prorrogação por interesse público das concessões de serviço público. E nossa hipótese de pesquisa é que esses pressupostos são bastante rígidos, dado o caráter excepcional do instituto da prorrogação.

O método de abordagem do tema é o dedutivo. E o método de pesquisa, o bibliográfico, consubstanciado na interpretação das diversas normas jurídicas (constitucionais e infraconstitucionais) que regulam o instituto da prorrogação no Brasil, à luz da jurisprudência e da doutrina.

Por fim, o presente artigo está dividido, basicamente, em duas seções. Na primeira, nós apresentaremos as espécies de prorrogação das concessões de serviço público, com vistas a determinarmos as características específicas da prorrogação por interesse público. Na segunda, nós verificaremos os pressupostos de validade para a realização dessa espécie de prorrogação. Ao final, exporemos, resumidamente, nossas principais conclusões.

\section{ESPÉCIES DE PRORROGAÇÃO}

Em nível constitucional, o fundamento normativo do instituto jurídico da prorrogação das concessões de serviço público reside na Constituição da República Federativa do Brasil de 1988 (CRFB/88), art. 175, par. ún., I, a qual estabelece que a lei disporá, dentre outras matérias, sobre a "prorrogação" dessas concessões.

No exercício da competência legislativa acima, foram editadas diversas leis ordinárias (gerais e setoriais) regulando a prorrogação das concessões de serviço público. Exemplo: (i) a Lei 8.987/95 (Lei de Concessões), art. 18, XIV; 23, XII; e 42, §§ 2. e 3..-; (ii) a Lei 11.079/04 (Lei de Parcerias Público-Privadas), art. 3.ํ, caput e § 1..-; 5., caput e I; e 11; (iii) a Lei 12.783/13 (Lei de Prorrogação do Setor Elétrico), art. 1.o a 16; 21, III; e 26; (iv) a Lei 12.815/13 (Lei do Setor Portuário), art. 57, 62, 66 e 67; e (v) a Lei 13.448/17 (Lei de Prorrogação dos Setores Rodoviário e Ferroviário), art. 1. a 11; 22; 24 a 27; 30; e 32 .

A interpretação sistemática das diversas leis gerais e setoriais sobre a matéria permitenos concluir que a prorrogação das concessões de serviço público - ou seja, o prolongamento

3 Cf., no âmbito do Estado de São Paulo, a recente Lei 16.933/19, art. 1.o a 7.o; 16; e 17. 
de seu prazo de vigência - pode ser classificada, basicamente, em três espécies; a saber: (i) a prorrogação por emergência; (ii) a prorrogação por reequilíbrio; e (iii) a prorrogação por interesse público, que se subdivide, por sua vez, em: (a) prorrogação comum; e (b) prorrogação antecipada $^{425}$.

Vejamos, então, quais são as características específicas dessas espécies de prorrogação, especialmente da última delas.

\subsection{Prorrogação por emergência}

A prorrogação por emergência visa a garantir a continuidade da prestação do serviço público concedido. Ela é realizada quando, próximo ao final da concessão, o Poder Concedente verifica que não tem condições de prestar, diretamente, o serviço público concedido nem tempo suficiente para realizar a licitação pública para nova outorga da atividade. Nesse caso, a concessão é prorrogada pelo tempo necessário para o Poder Concedente preparar-se para prestar, diretamente, o serviço público ou realizar a licitação pública para nova outorga da atividade - em regra, de seis a vinte e quatro meses.

Essa espécie de prorrogação está prevista, dentre outras, na Lei 13.448/17, a qual estabelece, em seu art. 32, que, se houver "estudo ou licitação em andamento", e se não houver "tempo hábil para que o vencedor do certame assuma o objeto do contrato", o Poder Concedente poderá "estender o prazo do contrato, justificadamente, por até vinte e quatro meses, a fim de que não haja descontinuidade na prestação do serviço"'.

Sobre o ponto, a jurisprudência já reconheceu a legitimidade da prorrogação por emergência. Com efeito, no AgRg no AREsp 481.094/RJ, o Superior Tribunal de Justiça (STJ) decidiu que, para evitar a "paralisação na prestação do serviço de transporte", "em completa afronta ao princípio da continuidade", uma permissão de serviço público pode ser prorrogada pelo prazo necessário à "conclusão do procedimento licitatório" (no caso, foi autorizada a prorrogação por "até um ano"), se, "em razão da desmobilização da infraestrutura estatal", for verificada a "impossibilidade de o ente público assumir, de forma direta, a prestação do referido serviço" ao término da outorga (BRASIL, 2014).

Por fim, a doutrina também admite a prorrogação por emergência das concessões de serviço público. De fato, Dallari (1988, p. 83-88) ensina que, "com fundamento no princípio da continuidade do serviço público", e com vistas a "evitar a interrupção abrupta e instantânea

\footnotetext{
4 Propomos as expressões "prorrogação por emergência”, "prorrogação por reequilíbrio" e "prorrogação por interesse público" ("comum" ou "antecipada”) para denominar as espécies de prorrogação das concessões de serviço público por sua relativa clareza e concisão. Nada obstante, reconhecemos que a expressão “prorrogação por interesse público" não é ideal, mas, apenas, utilitária, já que toda prorrogação visa, ao fim e ao cabo, a promover o interesse público - ademais, como toda medida administrativa destina-se a fazê-lo (finalidade genérica). Apesar desse problema de "rótulo", buscaremos demonstrar, nas seções abaixo, que as espécies de prorrogação das concessões de serviço público possuem características específicas inconfundíveis. Por fim, vale destacar que ainda existe grande divergência na doutrina acerca da terminologia adequada para nomear as espécies de prorrogação. Por exemplo, para denominar a prorrogação por emergência, Souto (2004, p. 404-406) utiliza a expressão "prorrogação emergencial”; Borges (2001, p. 861), a expressão "prorrogação excepcional”; e Nascimento (2017, p. 56), a expressão "prorrogação extraordinária”. Para designar a prorrogação por reequilíbrio, Schwind (2015, p. 495) faz uso da expressão "prorrogação-reequilíbrio"; Torgal (2011, p. 232), da expressão "prorrogação correctora”; e Canto e Guzela (2017, p. 212), da expressão "prorrogação extraordinária”. Por fim, para nomear a prorrogação por interesse público, Andrade (2015, p. 215-216) lança mão da expressão "prorrogação por motivos de conveniência e oportunidade”; Freitas (2017, p. 178), da expressão “prorrogação premial”; e Guimarães (2017, p. 58), da expressão “prorrogações ordinárias".

5 Algumas leis setoriais utilizam as expressões “prorrogação contratual” e "prorrogação antecipada” para denominar as subespécies de prorrogação por interesse público. Exemplo: a Lei 12.815/13, art. 57; e a Lei 16.933/19, art. 3.․․ I. Todavia, a nosso sentir, a expressão "prorrogação contratual” merece crítica. É que, tanto a “prorrogação não antecipada”, quanto a "prorrogação antecipada” prorrogam um contrato de concessão de serviço público, podendo, pois, ser chamadas de "prorrogação contratual”. Eis a razão pela qual, sem desconhecer a terminologia legal (e, principalmente, sem deixar de informá-la ao leitor), preferimos, para designar as subespécies de prorrogação por interesse público, fazer uso das expressões “prorrogação comum” e "prorrogação antecipada”, as quais, a nosso juízo, denotam, mais corretamente, seu objeto.

6 Cf., ainda: no âmbito federal, Lei 12.783/13, art. 9.'- e, no âmbito estadual, Lei 16.933/19, art. 16.
} 
de um determinado serviço" público ("que, por definição, é essencial”), "o Poder Público pode determinar ao concessionário que permaneça executando esse serviço por mais algum tempo", "até a sua integral regularização, o que se dará mediante a celebração de novas concessões, precedidas do indispensável procedimento licitatório"7.

\subsection{Prorrogação por reequilíbrio}

A prorrogação por reequilíbrio visa a recompor a relação inicial entre os encargos e a remuneração da concessionária sem a elevação do valor das tarifas, a redução das obrigações da concessionária e/ou o comprometimento de recursos públicos. Ela é realizada em caso de desequilíbrio econômico-financeiro da concessão, causado pela concretização de risco compreendido no conceito de álea extraordinária (administrativa ou econômica), atribuído, contratualmente, ao Poder Concedente - nomeadamente, a alteração unilateral do contrato, o fato do príncipe, o fato da Administração, as sujeições imprevistas e o caso fortuito ou força maior. Nesse caso, a concessão é prorrogada pelo prazo necessário à integral recomposição do equilíbrio econômico-financeiro inicial da outorga.

Essa espécie de prorrogação está prevista, dentre outros, no Decreto 7.624/11, o qual, ao dispor sobre as condições para a exploração do serviço público aeroportuário pela iniciativa privada em regime de concessão, estabelece, em seus art. 6.o e 18, II, que o prazo da outorga será definido pelo Poder Concedente, "podendo ser prorrogado uma única vez, por até cinco anos, para fins de reequilíbrio econômico-financeiro decorrente da efetivação de riscos não assumidos pela concessionária no contrato" ${ }^{\text {. }}$.

A propósito, a jurisprudência já afirmou a juridicidade da prorrogação por reequilíbrio. Com efeito, no Acórdão 774/16, que respondeu à consulta formulada pela Secretaria de Portos da Presidência da República, suscitando dúvida sobre a aplicação do instituto da prorrogação por reequilíbrio, o Tribunal de Contas da União (TCU) disse, "em conclusão", que a "recomposição econômico-financeira dos contratos de arrendamento portuário [que muito se assemelham aos contratos de subconcessão de serviço público $\left.{ }^{9}\right]$ poderá ser implementada, justificadamente, por meio de alargamento do prazo contratual" (BRASIL, 2016).

Por derradeiro, a doutrina também apoia a prorrogação por reequilíbrio das concessões de serviço público. De fato, Amaral (2012, p. 16-30) leciona que a prorrogação por reequilíbrio busca "corrigir eventual desequilíbrio econômico-financeiro" da concessão, tendo lugar - "independentemente de constar do contrato cláusula de prorrogação" - em razão de "desequilíbrio econômico-financeiro" causado pela concretização de "risco contido na álea extraordinária", pelo prazo "estritamente necessário ao reequilíbrio"

\subsection{Prorrogação por interesse público}

A prorrogação por interesse público visa a promover a prestação adequada do serviço público. Ela é realizada por razões de conveniência e oportunidade das partes, desde que os pressupostos de validade da medida estejam presentes ${ }^{11}$ e a concessionária aceite determinadas condições (ou contrapartidas) propostas pelo Poder Concedente, caracterizadoras da vantagem

7 Cf., ainda: CÂMARA, 2014, p. 347; MORAIS, 1957, p. 447-457.

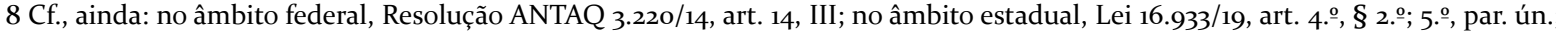

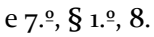

9 MOREIRA NETO; FREITAS, 2015, p. 83-84 e 88

10 Cf., ainda: JUSTEN FILHO, 2016, p. 128-129 e 131-134; SANTOS, 2006, p. 108-110.

11 Os pressupostos de validade da prorrogação por interesse público serão apresentados na seção 2 abaixo. 
da prorrogação vis-à-vis as alternativas da prestação direta do serviço público e da realização de licitação pública para nova outorga da atividade ${ }^{12}$. Nesse caso, a concessão é prorrogada pelo prazo previsto em lei ou no próprio ajuste.

Essa espécie de prorrogação está prevista, dentre outras, na Lei 9.472/97, a qual dispõe, em seu art. 99, que o prazo de vigência das concessões do serviço público de telecomunicações será, no "máximo", de "vinte anos", podendo ser prorrogado "uma única vez, por igual período", desde que a concessionária "tenha cumprido as condições da concessão" e aceite os "condicionamentos" propostos pela Agência Nacional de Telecomunicações (Anatel) em vista das circunstâncias vigentes à época - dentre outros, o "pagamento" pelo prolongamento da outorga do "direito de exploração do serviço"ı.

Sobre o ponto, a jurisprudência já reconheceu a legitimidade da prorrogação por interesse público. Com efeito, no Acórdão 2.200/15, o TCU decidiu que a prorrogação dos contratos de arrendamento portuário "não afronta o princípio de índole constitucional de prévia licitação para a celebração de contratos", desde que: (i) a celebração de tais ajustes tenha sido precedida de "regular procedimento licitatório"; e (ii) a prorrogação seja condicionada à realização de "novos investimentos" na infraestrutura portuária (BRASIL, 2015b).

E, no Acórdão 2.253/15, o TCU considerou "constitucional" a prorrogação simultânea de quarenta e três concessões do serviço público de distribuição de energia elétrica com vencimento até 2017 (desde que as concessionárias aceitassem as novas metas de qualidade e de gestão econômico-financeira definidas pela Agência Nacional de Energia Elétrica), porque entendeu caracterizadas "situações de exceção" que justificavam a não realização de licitação pública (BRASIL, 2015a) ${ }^{14}$.

Por fim, a doutrina também admite a prorrogação por interesse público das concessões de serviço público. De fato, Mello, C. (2009, p. 57) ensina que as concessões de serviço público podem ser prorrogadas "por simples convicção da conveniência e oportunidade administrativa da extensão de seu prazo", neste caso, desde que haja: (i) "previsão legal autorizadora"; (ii) "possibilidade [...] acolhida no edital"; (iii) "bom desempenho do concessionário"; e (iv) "interesse de ambos na continuidade daquele vínculo" ${ }^{15}$.

\subsubsection{Subespécies de prorrogação por interesse público}

Segundo o momento em que é realizada, a prorrogação por interesse público pode ser classificada em: (i) prorrogação comum; e (ii) prorrogação antecipada ${ }^{16}$.

Vejamos, então, no que consiste cada uma delas.

\subsubsection{Prorrogação comum}

Prorrogação comum é aquela realizada ao final da concessão.

\footnotetext{
12 Exemplo: (i) o pagamento pela prorrogação da outorga; (ii) a realização de novos investimentos na concessão; e (iii) a extinção do caráter de exclusividade da outorga.

${ }_{13}$ Cf., ainda: no âmbito federal, Lei 9.074/95, art. 19 c.c 25; e, no âmbito estadual, Lei 16.933/19, art. 3.ำ I e II.

14 Outro precedente importante será a decisão do TCU sobre a prorrogação da concessão da Rumo-Malha Paulista, leading case em matéria de prorrogação antecipada de concessões ferroviárias na Corte. A propósito, a Agência Nacional de Transportes Terrestres já aprovou a referida prorrogação, que agora aguarda o aval da Corte de Contas. O TCU ainda não tem data para decidir sobre a matéria. Mas o Ministério Público de Contas apresentou, recentemente, parecer recomendando a "rejeição" da medida "em razão da ausência de vantagem na prorrogação do contrato em relação à realização de nova licitação".

15 Cf., ainda: GARCIA, 2015, p. 416-426; MARQUES NETO, 2015, p. 167-171.

16 Guimarães e Gaggiano (2017, p. 12) também entendem que "[a] distinção entre elas [ou seja, entre a prorrogação comum e a prorrogação antecipada] é mais cronológica do que de essência", sendo certo que "[o] que distingue as duas medidas é o momento de implementação".
} 
Essa subespécie de prorrogação por interesse público está prevista, dentre outras, na Lei $13.448 / 17$, a qual estabelece, em seu art. $4 .^{\circ}$, I, que a prorrogação comum das concessões dos serviços públicos rodoviário e ferroviário é aquela realizada ao "término da vigência do ajuste"17.

\subsubsection{Prorrogação antecipada}

Prorrogação antecipada é aquela realizada antes do final da concessão, respeitado, porém, o limite máximo de antecipação previsto em lei ou, subsidiariamente, no próprio ato de outorga ${ }^{18}$.

Essa subespécie de prorrogação por interesse público está prevista, dentre outras, na Lei 12.783/13, a qual estabelece, em seu art. 12, que o Poder Concedente poderá "antecipar os efeitos da prorrogação" das concessões do serviço público de energia elétrica, respeitado o limite máximo de antecipação de "até 60 (sessenta) meses do advento do termo contratual"19.

Vistas as características específicas da prorrogação por interesse público (comum ou antecipada), vejamos, agora, seus pressupostos de validade.

\section{PRESSUPOSTOS}

Pressupostos são as circunstâncias sem as quais a prorrogação por interesse público (comum ou antecipada) não pode ser realizada validamente.

A nosso sentir, esses pressupostos são: (i) previsão em lei; (ii) outorga precedida de licitação; (iii) previsão no edital de licitação; (iv) concessão em vigor; (v) não realização de prorrogação por interesse público anteriormente; (vi) fiel cumprimento do contrato pela concessionária; (vii) vantajosidade da medida; (viii) consenso entre as partes; e (ix) qualificação no PPI.

Vejamos, então, o fundamento de cada um deles.

\subsection{Previsão em lei}

Para que a prorrogação por interesse público (comum ou antecipada) seja realizada validamente, é preciso, primeiro, que a possibilidade de prorrogação esteja prevista em lei.

É o que extraímos não apenas da reserva de lei estabelecida pela CRFB/88, art. 175, caput (que exige autorização legislativa para a delegação de serviços públicos - e, coerentemente, para a prorrogação dessa delegação), mas também da Lei 8.666/93, a qual prevê, em seu art. 92 c.c 124, que a "prorrogação" das concessões de serviço público "sem autorização em lei" constitui crime.

A propósito, a doutrina também afirma que a prorrogação por interesse público pressupõe autorização em lei. De fato, Meirelles (1982, p. 405-413) ensina que, "[p]ara a concessão originária, sua renovação ou prorrogação ou nova concorrência do mesmo serviço, haverá, sempre, necessidade de autorização por lei, regulamentação por decreto e transferência da execução por contrato”, já que a regra é a prestação direta do serviço público; e arremata: “Toda

17 Cf., ainda: no âmbito federal, Lei 9.472/97, art. 99; e, no âmbito estadual, Lei 16.933/19, art. 3.ำ I.

$18 \mathrm{O}$ limite máximo de antecipação varia caso a caso conforme a(s) finalidade(s) específica(s) da prorrogação antecipada, sendo

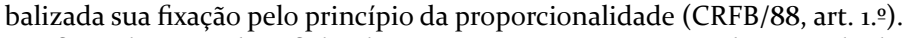

19 Cf., ainda: no âmbito federal, Lei 12.815/13, art. 57; e, no âmbito estadual, Lei 16.933/19, art. 3.․․ II. 
prorrogação de concessão de serviço público depende de autorização legislativa ao término de cada período contratual"2o.

Por fim, é preciso dar destaque ao presente pressuposto, porquanto ele serve para distinguir, de um lado, a prorrogação por interesse público e, de outro, as prorrogações por emergência e por reequilíbrio. Com efeito, entendemos que, diferentemente da prorrogação por interesse público, as prorrogações por emergência e por reequilíbrio podem ser realizadas sem expressa permissão em lei, uma vez que elas têm lugar diante de situações excepcionais, imprevisíveis no momento da outorga, respectivamente: a proximidade do término da concessão, sem que o Poder Concedente tenha condições de prestar, diretamente, o serviço público concedido nem tempo suficiente para realizar a licitação pública para nova outorga da atividade; e o desequilíbrio econômico-financeiro da concessão causado pela concretização de risco compreendido no conceito de álea extraordinária ${ }^{21}$.

\subsection{Outorga precedida de licitação}

Para que a prorrogação por interesse público (comum ou antecipada) seja realizada validamente, é preciso, ainda, que a outorga da concessão de serviço público tenha sido precedida de licitação pública.

É o que extraímos não apenas da CRFB/88, art. 175, caput, que estabelece que toda concessão de serviço público será precedida, "sempre", de "licitação", mas também das Leis 8.987/95, art. 14, e 11.079/04, art. 10, que reafirmam essa exigência.

Sobre o ponto, a jurisprudência já reconheceu que concessão de serviço público outorgada sem prévia licitação pública - mesmo antes da entrada em vigor da CRFB/88 não pode ser prorrogada. De fato, no ARE 869.007/DF-ED-AgR, o Supremo Tribunal Federal (STF) decidiu que, "nos termos do art. 175, caput, da Constituição Federal, é imprescindível prévia licitação para a concessão ou a permissão da exploração de serviços públicos", razão pela qual "são inconstitucionais as prorrogações de concessão e de permissão que vão de encontro à referida premissa, inclusive as de contratos formalizados antes de 5 de outubro de 1988" (BRASIL, 2017).

Por derradeiro, a doutrina também afirma que a prorrogação por interesse público pressupõe outorga precedida de licitação. Com efeito, Rocha (1996, p. 6o-61) leciona que, "[p] ara durar além do termo inicialmente estabelecido, urge, em primeiro lugar, que a concessão tenha sido contratada segundo o Direito”, pois “a prorrogação não é fórmula mágica permissiva de convalidação de vícios havidos na outorga da concessão, nem alarga, no tempo futuro, o que não pode existir no Direito vigente em determinado momento"22.

\subsection{Previsão no edital de licitação}

Para que a prorrogação por interesse público (comum ou antecipada) seja realizada validamente, é preciso, ainda, que a possibilidade de prorrogação esteja prevista no edital de licitação.

É o que extraímos não apenas do princípio da vinculação ao instrumento convocatório (Leis 8.987/95, art. 14; e 11.079/o4, art. 12), mas também da Lei 8.666/93, a qual estabelece, em

20 Cf., ainda: BARCELLOS, 2017, p. 177; CLÈVE, 2012, p. 10 e 29.

21 Cf. FREITAS; RIBEIRO, 2017, p. 297-298.

22 Cf., ainda: AMORIM, 2013, p. 58; TORGAL, 2011, p. 234-235. 
seu art. 92 c.c 124, que a prorrogação das concessões de serviço público "sem autorização [...] no ato convocatório da licitação" constitui crime.

A propósito, a doutrina também afirma que a prorrogação por interesse público pressupõe autorização no edital de licitação - uma vez que tal circunstância possui aptidão para alterar as propostas dos licitantes (a simples a previsão/não previsão da possibilidade de prorrogação por interesse público no edital de licitação torna a concessão, enquanto atividade econômica, financeiramente mais ou menos atraente para os investidores). De fato, Mello, C. (2009, p. 57) ensina que a prorrogação por interesse público "depende de expressa previsão legal e contratual", sob pena de "burla ao princípio da licitação, já que outros, se soubessem, antecipadamente, de tal possibilidade aberta pela lei e acolhida no edital, poderiam ter acorrido ao certame ou, os que acorreram, poderiam ter feito oferta distinta da que fizeram"23.

Por fim, é preciso realçar o presente pressuposto, porquanto ele também serve para distinguir, de um lado, a prorrogação por interesse público e, de outro, as prorrogações por emergência e por reequilíbrio. Com efeito, entendemos que, diferentemente da prorrogação por interesse público, as prorrogações por emergência e por reequilíbrio podem ser realizadas sem permissão no edital de licitação, uma vez que, além de não terem aptidão para alterar as propostas dos licitantes, tais espécies de prorrogação têm lugar diante de situações excepcionais, imprevisíveis no momento da outorga, como visto na seção 2.1 acima $^{24}$.

\subsection{Concessão em vigor}

Para que a prorrogação por interesse público (comum ou antecipada) seja realizada validamente, é preciso, ainda, que a concessão esteja em vigor.

É o que extraímos, dentre outras, da Lei 12.815/13, a qual estabelece, em seu art. 57, que somente os contratos de arrendamento portuário "em vigor" poderão ser prorrogados.

Não fosse o bastante, é o que colhemos, ainda, da natureza jurídica do instituto sob análise. De fato, a prorrogação por interesse público possui natureza jurídica de negócio acessório, ou seja, não tem existência própria, pressupondo a do negócio principal, e seguindo a sorte deste. Assim sendo, extinta a concessão de serviço público, a prorrogação por interesse público torna-se juridicamente impossível por falta de objeto.

Sobre o ponto, a jurisprudência já reconheceu que concessão de serviço público extinta não pode ser prorrogada. Com efeito, na AMS oooo274-24.2004.4.03.6104/SP, o Tribunal

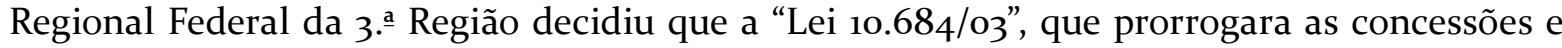
permissões do serviço público de armazenagem e movimentação de mercadorias em estação aduaneira interior vigentes em "30.05.2003", não se aplicava a uma permissão finda em "23.05.2003", "pois, afinal, não se prorroga contrato inexistente" (BRASIL, 2010).

Por sua vez, a doutrina também afirma que a prorrogação por interesse público pressupõe concessão em vigor. De fato, Meirelles (2002, p. 228-230) leciona que, nos "contratos que se extinguem simplesmente ao término do prazo" (como a "concessão de serviço público"), "[a] expiração do prazo de vigência sem prorrogação opera, de pleno direito, a extinção do contrato", sendo certo que "[o] contrato extinto não se prorroga nem se renova: é refeito e formalizado em novo instrumento, inteiramente desvinculado do anterior"; por fim, o autor acrescenta: "[s] e a prorrogação não foi providenciada pela Administração antes de vencido o prazo contratual [...] será considerado irregular o instrumento de prorrogação feito posteriormente", inclusive, "para a responsabilização dos agentes públicos envolvidos"

23 Cf., ainda: SAADI; SANTOS NETO, 2016, p. 87 e 105; SCHWIND, 2015, p. 502-505.

24 Cf. MELLO, R., 2014, p. 212 e 218-220.

25 Cf., ainda: FARIA, 1999, p. 385; TELLES, 2000, p. 240 
Neste momento, é preciso considerar o entendimento de Beznos (1991, p. 268), para quem a prorrogação por interesse público pode ser realizada depois do término da concessão, desde que o "pedido de prorrogação" tenha sido protocolado pela concessionária "com antecedência [...] do termo final da avença", já que "[t]al tempestiva manifestação de vontade [...] revelase suficiente para fazer integrar ao seu patrimônio o direito à prorrogação, não se podendo penalizá-la com a demora administrativa para a formalização da mesma prorrogação".

Sem desprestigiar, de modo algum, tão eminente administrativista, nós discordamos, respeitosamente, de seu entendimento. Com efeito, afora a impossibilidade jurídica de prorrogação de concessão extinta, entendemos que a prorrogação por interesse público também possui natureza jurídica de negócio bilateral, formando-se, pois, a partir de um acordo de vontades entre Poder Concedente e concessionária de serviço público. Assim sendo, não nos parece que a simples manifestação de vontade da concessionária seja "suficiente para fazer integrar ao seu patrimônio o direito à prorrogação" antes de o Poder Concedente verificar a conveniência e oportunidade da medida administrativa.

Em verdade, entendemos que o Poder Concedente deve servir-se da prorrogação por emergência, se, protocolado o pedido de prorrogação pela concessionária, ele verificar que não terá tempo suficiente para decidir sobre a matéria antes da extinção da concessão, valendose, posteriormente, da prorrogação por interesse público, caso constate a conveniência e oportunidade da medida.

\subsection{Não realização de prorrogação por interesse público anteriormente}

Para que a prorrogação por interesse público (comum ou antecipada) seja realizada validamente, é preciso, ainda, que a concessão de serviço público não tenha sido prorrogada anteriormente por meras razões de conveniência e oportunidade das partes.

É o que extraímos, dentre outras:

(i) da Lei 9.472/97, a qual estabelece, em seu art. 99, que as concessões do serviço público de telecomunicações só poderão ser prorrogadas "uma única vez";

(ii) da Lei 12.815/13, a qual dispõe, em seu art. 57, que a prorrogação dos contratos de arrendamento portuário só terá lugar, se "ainda não realizada”; e

(iii) da Lei 13.448/17, a qual prevê, em seu art. 5.․․ § 3.‥, que as concessões rodoviárias e ferroviárias poderão ser prorrogadas "uma única vez", "desde que já não tenham sido prorrogadas anteriormente".

Em verdade, entendemos que o pressuposto sob análise decorre da própria Constituição Federal. Explicamos. Ao tratar do prolongamento do prazo de vigência das concessões de serviço público por meras razões de conveniência e oportunidade das partes, a CRFB/88, art. 175, par. ún., I; e 223, recorreu aos institutos da "prorrogação" e da "renovação", atribuindo, coerentemente, regimes jurídicos distintos a eles. A possibilidade de prolongamentos sucessivos é uma das características específicas do regime jurídico do instituto da renovação (CRFB/88, art. 223, § 2.ํ). A nosso sentir, as características específicas do regime jurídico do instituto da renovação não podem ser replicadas nas leis que regulam o instituto da prorrogação por interesse público, sob pena de igualar-se aquilo que o legislador constituinte originário intencionalmente diferenciou. Assim sendo, concluímos, a partir da interpretação sistemática da CRFB/88, art. 175, par. ún., I; e 223, que as concessões dos demais serviços públicos (que não o de radiodifusão) não podem ser prolongadas por períodos sucessivos ${ }^{26}$.

26 Neste momento, vale a pena fazer uma brevíssima digressão para dizer que, a nosso sentir, a possibilidade de prolongamentos sucessivos das concessões de radiodifusão só foi admitida pelo legislador constituinte de 1988 (que amargara o autoritarismo da ditadura militar) em razão da especial relevância do serviço público de radiodifusão para o exercício da cidadania (CRFB/88, art. 
É claro que poderíamos chegar à mesma conclusão - isto é, à proibição de prorrogações sucessivas - por outro caminho constitucional, mais precisamente, recorrendo ao dogma jurídico da inalienabilidade das competências públicas e aos princípios da isonomia/impessoalidade (CRFB/88, art. 5. e 37), moralidade/probidade (CRFB/88, art. 37) e eficiência/economicidade (CRFB/88, art. 37 e 70), que vedam a perpetuação de outorgas de serviço público e impõem ao Estado o dever de relicitar, de tempos em tempos, o direito de exploração da atividade econômica consubstanciada no serviço público - isto é, de convidar o mercado a concorrer, mais uma vez, pelo referido direito. Todavia, a nosso sentir, a interpretação sistemática da $\mathrm{CRFB} / 88$, art. 175, par. ún., I; e 223, permite reconhecer, com maior concretude, o pressuposto sob exame.

A propósito, a jurisprudência já reconheceu que a prorrogação por interesse público não pode ser realizada de maneira sucessiva. De fato, no REsp 912.402/GO, o STJ decidiu que, conquanto a Lei 8.987/97 não estabeleça "limitação do prazo de prorrogação" das concessões ou permissões do serviço público de "loteria", tais outorgas não podem ser prorrogadas de maneira "sucessiva", sem a abertura de novo procedimento licitatório, uma vez que "[a] prorrogação indefinida do contrato é forma de subversão às determinações legais e constitucionais que versam sobre o regime de concessão e permissão para exploração de serviços públicos” (BRASIL, 2009).

E, no Acórdão 574/o6, que tratou da prorrogação sucessiva dos contratos de franquia celebrados entre a Empresa Brasileira de Correios e Telégrafos e as Agências de Correio Franqueadas, o TCU decidiu que era "flagrante a inconstitucionalidade" da Lei 10.577/o2, que prorrogara "por mais 5 anos" os referidos ajustes, uma vez que: (i) a CRFB/88, art. 21, $\mathrm{X}$, classifica o serviço postal como "serviço público"; (ii) a CRFB/88, art. 175, estabelece que a prestação indireta de serviços públicos pelo Estado far-se-á, "sempre, através de licitação"; e (iii) "[d]e vigência inicialmente prevista para 1998, os contratos foram por diversas vezes prorrogados, até que esta última Lei os elasteceu até 2007, ou 9 anos a mais" (BRASIL, 2006).

Por sua vez, diversos doutrinadores de escol também afirmam que a prorrogação por interesse público pressupõe a não realização de prorrogação por conveniência e oportunidade anteriormente. Com efeito, Clève (2012, p. 13, 21 e 30) ensina que "há disposição constitucional expressa admitindo a existência de prorrogação"; mas "o prazo da concessão deve ser, de outra parte, determinado, não sendo admissíveis sucessivas prorrogações, notadamente para evitar que as concessões eternizem-se, perpetuem-se, ensejando burla e fraude ao requisito da prévia licitação"; e acrescenta: "Convém lembrar que, com razão, têm sido objeto de severa crítica doutrinária [...] as concessões outorgadas sem prévia licitação, as concessões que permitem inúmeras prorrogações, as concessões cujas prorrogações são arbitrárias e/ou vinculadas a exigências subjetivas" ${ }^{27}$.

Nada obstante, é preciso dizer que alguns doutrinadores admitem a prorrogação sucessiva das concessões de serviço público, desde que prevista em lei e no edital de licitação/ contrato de concessão. Dentre outros, é o caso de Sundfeld e Câmara (2013, p. 64-65), para quem a Lei de Concessões "foi aberta em relação à prorrogação desses contratos": "indicou a necessidade de tratar contratualmente o assunto, mas não fez qualquer determinação sobre o conteúdo a ser estabelecido sobre essa matéria"; por isso, "[o]s requisitos para a prorrogação, inclusive o número de vezes em que será admitida, devem ser disciplinados no próprio

1. - , II). De fato, a radiodifusão é relevante para a cidadania, porque possibilita a transmissão de informações políticas e sociais de interesse geral com penetração social (em número e variedade de público) maior do que qualquer outro meio de comunicação; e a renovação sucessiva é relevante para a radiodifusão, porque, ao estabilizar a outorga, ela possibilita a transmissão livre e veraz dessas informações. Assim sendo, a possibilidade de renovações sucessivas das outorgas de radiodifusão faz parte de um microssistema jurídico de proteção da liberdade de informação, o qual busca evitar que as emissoras de televisão e de rádio que transmitam informações ou manifestem pontos de vista contrários aos interesses dos poderosos em geral sejam afastadas, facilmente, do Setor de Radiodifusão, em prejuízo da sociedade. Cf., ainda: FAGUNDES, 1961, p. 51-53; MARQUES NETO, 2015, p. 225-226; RODRIGUES JUNIOR, 2005, p. 245-246.

27 Cf., ainda: BARROSO, 2007, p. 272.; MARQUES NETO, 2015, p. 169-170. 
contrato"; por fim, os autores afirmam que, no "Setor de Radiodifusão", a própria "Constituição Federal assegura a continuidade do vínculo, autorizando - e, até, incentivando - a prorrogação sucessiva das concessões".

Sem desprestigiar, de modo algum, tão eminentes administrativistas, nós discordamos, respeitosamente, de seu entendimento. De fato, entendemos, a partir das razões normativas (constitucionais e infraconstitucionais), jurisprudenciais e doutrinárias acima, que, ao contrário da renovação das concessões de radiodifusão, a prorrogação por interesse público (comum ou antecipada) das demais concessões de serviço público só pode ser realizada uma única vez, vedada, portanto, a possibilidade de prorrogações sucessivas - mesmo que tal possibilidade esteja prevista em lei e no edital de licitação/contrato de concessão (previsões que, a nosso sentir, são inválidas).

Em verdade, parece-nos que a prorrogação sucessiva das concessões de serviço público por razões de conveniência e oportunidade das partes é uma contrafação administrativa real ${ }^{28}$ de renovação das concessões de radiodifusão, tomada a CRFB/88, art. 223, como parâmetro.

\subsection{Fiel cumprimento do contrato pela concessionária}

Para que a prorrogação por interesse público (comum ou antecipada) seja realizada validamente, é preciso, ainda, que a concessionária de serviço público esteja cumprindo, fielmente, seu contrato de concessão - e, por conseguinte, prestando serviço adequado aos usuários.

É o que extraímos, dentre outras, da Lei 13.448/17, a qual estabelece, em seu art. 6.., § 2.- , II, que a prorrogação antecipada das concessões do serviço público ferroviário pressupõe a "prestação de serviço de transporte ferroviário adequado" pela concessionária, entendendo-se, como tal, "o cumprimento [...] das metas de produção e de segurança definidas no contrato"29.

Em verdade, parece-nos que o pressuposto sob análise decorre da própria Constituição Federal, a qual estabelece, em seu art. 175, par. ún. I e IV, que a lei disporá sobre a "prorrogação" das concessões de serviço público, sem prejuízo da "obrigação [do Estado] de manter serviço adequado".

Sobre ponto, a jurisprudência já reconheceu que as concessões de serviço público só podem ser prorrogadas, se a concessionária estiver cumprindo seu contrato de concessão. De fato, no recente Acórdão 1.171/18, que tratou da prorrogação antecipada do contrato de arrendamento portuário celebrado entre a Companhia Docas do Estado de São Paulo (Codesp) e o Grupo Libra, o TCU decidiu que tal prorrogação era "irregular" em razão do histórico de descumprimentos contratuais da arrendatária - a saber: (i) a "Libra não pagou integralmente à Codesp os valores do arrendamento portuário"; e (ii) "a arrendatária nunca atingiu a movimentação projetada para os terminais" (BRASIL, 2018b).

Por derradeiro, a doutrina também afirma que a prorrogação por interesse público pressupõe o fiel cumprimento do contrato de concessão pela concessionária. Com efeito, Nascimento (2017, p. 52 e 55) leciona que "há de se ter em mente que a simples boa conduta do concessionário não pode ser condição para a prorrogação, mas, sim, em todos os casos, um requisito para definir se vale a pena considerar o prolongamento da relação entre o Concedente e o concessionário"; e acrescenta: "o comportamento pretérito - serviço adequado - é requisito de admissibilidade da prorrogação como opção a ser considerada e deve ser aferido por critérios objetivos indicados no contrato original" 3 .

28 MARTINS, 2016, p. 117-119 e 127-128.

29 Cf., ainda: no âmbito federal, Lei 9.472/97, art. 99; e, no âmbito estadual, Lei 16.933/19, art. 7.으, § 2.․․

3o Cf., ainda: ARAGÃO, 2013, p. 554; AZEVEDO; ALENCAR, 1998, p. 101-102. 


\subsection{Vantajosidade da medida}

Para que a prorrogação por interesse público (comum ou antecipada) seja realizada validamente, é preciso, ainda, que se verifique uma situação excepcional, caracterizadora da vantajosidade da medida vis-à-vis as alternativas da prestação direta do serviço público e da realização de licitação pública para nova outorga da atividade - situação essa avaliada pelo Poder Concedente com base em um juízo de conveniência e oportunidade (discricionariedade administrativa).

É o que extraímos, dentre outras, da Lei 13.448/17, a qual estabelece, em seu art. 8., que o Poder Concedente deve demonstrar, por meio de "estudo técnico prévio", a "vantagem" da prorrogação das concessões rodoviárias e ferroviárias "em relação à realização de nova licitação para o empreendimento"31.

Em verdade, entendemos que o pressuposto sob análise também decorre da própria Constituição Federal. Explicamos. A CRFB/88, art. 175, par. ún., I, estabelece, expressamente, que a prorrogação das concessões de serviço público possui "caráter especial". Etimologicamente, a palavra "especial" significa aquilo "que não é geral" (HOUAISS; VILLAR, 2009, p. 814). No contexto da prorrogação por interesse público, isso significa, a nosso sentir, que o prolongamento de prazo tem lugar, apenas e tão somente, diante de situação especial (ou melhor, excepcional), caracterizadora da vantagem da prorrogação vis-à-vis às alternativas da prestação direta do serviço público e da realização de licitação pública para nova outorga da atividade ao final da concessão (CRFB/88, art. 175, caput).

A propósito, a jurisprudência já reconheceu que a prorrogação por interesse público só pode ser realizada, se for vantajosa para o Poder Concedente. De fato, no Acórdão 2.200/15, que tratou da prorrogação antecipada dos contratos de arrendamento portuário, o TCU decidiu que "a prorrogação [...] demanda a demonstração prévia e inequívoca de que as condições do contrato em vigor permanecem vantajosas para a Administração, quando comparadas com o que se poderia obter no mercado por meio de nova licitação" (BRASIL, 2015b).

Por fim, a doutrina também afirma que a prorrogação por interesse público pressupõe a vantajosidade da medida. Com efeito, Torgal (2011, p. 229-230) ensina que a prorrogação por interesse público só tem lugar, quando, a partir de uma "ponderação", o Poder Concedente concluir pela "existência [...] de interesse em permitir ao concessionário o exercício dos direitos outorgados pelo contrato por um período adicional", juízo que só será positivo, quando "se verificar que a actuação pretérita do co-contratante justifica um renovado voto de confiança" e, sobretudo, quando "se estimar que, tudo ponderado, essa solução prossegue, mais cabalmente, o interesse público do que as alternativas de exercício pela Administração das actividades em causa ou de abertura de um procedimento concorrencial visando à escolha de uma nova proposta para o efeito"32.

\subsection{Consenso entre as partes}

Para que a prorrogação por interesse público (comum ou antecipada) seja realizada validamente, é preciso, ainda, que haja consenso entre Poder Concedente e concessionária.

É o que extraímos, dentre outras, da Lei 9.472/97, a qual estabelece, em seu art. 99, que as concessões do serviço público de telecomunicações poderão ser prorrogadas, "desde que a concessionária manifeste expresso interesse na prorrogação”, sendo certo que, nesse caso,

${ }_{11}$ Cf., ainda: no âmbito federal, Lei 8.666/93, art. 57, II (por analogia); e, no âmbito estadual, Lei 16.933/19, art. 7.․ . 32 Cf., ainda: CANTO; GUZELA, 2017, p. 212; GARCIA, 2015, p. 593-594. 
a Anatel decidirá sobre a matéria a seu "critério [...] tendo em vista as condições vigentes à época"33.

Não fosse o bastante, é o que colhemos, ainda, da natureza jurídica do instituto sob análise. De fato, na seção 2.4 acima, vimos que a prorrogação por interesse público tem natureza jurídica de negócio bilateral, formando-se, pois, a partir do acordo de vontades entre Poder Concedente e concessionária de serviço público. Assim sendo, ela não pode ser imposta, unilateralmente, pelo Poder Concedente, nem exigida pela concessionária.

Sobre o ponto, a jurisprudência já reconheceu que a prorrogação por interesse público possui caráter bilateral, pressupondo, pois, o consenso entre as partes. Com efeito, no RMS 34.203/DF, o STF deixou dito que a "bilateralidade" é uma "característica" da prorrogação por interesse público, pelo que existe, sempre, "a necessidade de manifestação das concessionárias quanto ao interesse de permanecer sob a contratação" (BRASIL, 2018a).

Por sua vez, a doutrina também afirma que a prorrogação por interesse público pressupõe consenso entre Poder Concedente e concessionária. Com efeito, Garcia (2015, p. 601-602) leciona que "[p]onto inconteste é que a prorrogação do prazo não é uma daquelas cláusulas exorbitantes que podem ser unilateralmente impostas pela Administração Pública ou, mesmo, no caso de recusa da sociedade empresária contratada, resultar em aplicação de qualquer sanção administrativa"; e acrescenta: "Trata-se de ato bilateral e convencional, que assegura ao contratado o direito de não permanecer no vínculo contratual além daquele prazo originalmente fixado, salvo por expressa vontade própria"34.

Por fim, é preciso dar destaque ao presente pressuposto, porquanto ele também serve para distinguir, de um lado, a prorrogação por interesse público e, de outro, as prorrogações por emergência e por reequilíbrio. De fato, entendemos que, diferentemente da prorrogação por interesse público, as prorrogações por emergência e por reequilíbrio podem ser impostas, unilateralmente, pelo Poder Concedente à concessionária de serviço público: a primeira, com fundamento no princípio da continuidade dos serviços públicos (CRFB/88, art. 175, par. ún.,

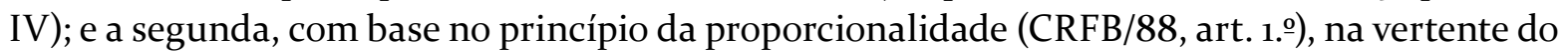
cumprimento do dever de recompor o equilíbrio econômico-financeiro da concessão do modo menos oneroso para o Poder Concedente ${ }^{35}$.

\subsection{Qualificação no Programa de Parcerias de Investimentos - PPI}

Por derradeiro, especificamente em relação à prorrogação por interesse público (comum ou antecipada) das concessões rodoviárias e ferroviárias, a Lei 13.448/17, art. 2..o, estabelece que somente poderão ser prorrogados as concessões dessa espécie previamente "qualificados para esse fim no Programa de Parcerias de Investimentos - PPI".

A propósito, vale ressaltar que o referido programa de governo foi criado pela Medida Provisória 727/16, posteriormente convertida na Lei $13.334 / 16$, com vistas a promover a execução (estruturação e/ou a liberação) de empreendimentos de infraestrutura públicos ou privados considerados prioritários para o País (art. 1.․․ 5. e 21). E que a qualificação (leia-se: a inclusão) de um empreendimento de infraestrutura no PPI é feita por decreto do Presidente da República, ouvido, previamente, o Conselho do PPI (art. 4.ํ, II c.c 7.ํ, I).

Apresentados os pressupostos da prorrogação por interesse público, vejamos, agora, as principais conclusões deste artigo.

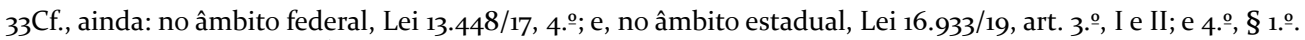
34 Cf., ainda: CRETELLA JÚNIOR, 1996, p. 168; GONÇALVES, 1999, p. 328.

35 Cf. REALE, 1969, p. 65; TORGAL, 2011, p. 255-256. 


\section{CONCLUSÃO}

Ao fim deste artigo, expomos, resumidamente, nossas principais conclusões:

(i) em nível constitucional, o fundamento do instituto da prorrogação das concessões de serviço público reside na $\mathrm{CRFB} / 88$, art. 175, par. ún., I; e, em nível infraconstitucional, em diversas leis e regulamentos;

(ii) a prorrogação das concessões de serviço público - isto é, o prolongamento de seu prazo de vigência - pode ser classificada, basicamente, em três espécies; a saber: (a) a prorrogação por emergência; (b) a prorrogação por reequilíbrio; e (c) a prorrogação por interesse público;

(iii) prorrogação por interesse público é aquela realizada por razões de conveniência e oportunidade das partes, desde que os pressupostos de validade da medida estejam presentes e a concessionária aceite determinadas condições (ou contrapartidas) propostas pelo Poder Concedente, caracterizadoras da vantagem da prorrogação vis-à-vis as alternativas da prestação direta do serviço público e da realização de licitação pública para nova outorga da atividade;

(iv) as subespécies de prorrogação por interesse público são: (a) a prorrogação comum; e (b) a prorrogação antecipada;

(v) prorrogação comum é aquela realizada ao final da concessão; e prorrogação antecipada, aquela realizada antes do final da concessão, respeitado, porém, o limite máximo de antecipação previsto em lei ou, subsidiariamente, no próprio ato de outorga;

(vi) dado o caráter excepcional do instituto da prorrogação, a prorrogação por interesse público (comum ou antecipada) está sujeita a rígidos pressupostos de validade, ou seja, circunstâncias sem as quais ela não pode ser realizada validamente; e

(vii) com base nas razões normativas, jurisprudenciais e doutrinárias apresentadas, os pressupostos de validade da prorrogação por interesse público (comum ou antecipada) são: (a) previsão em lei; (b) outorga precedida de licitação; (c) previsão no edital de licitação; (d) concessão em vigor; (e) não realização de prorrogação por interesse público anteriormente; (f) fiel cumprimento do contrato pela concessionária; (g) vantajosidade da medida; (h) consenso entre as partes; e, exclusivamente para a prorrogação das concessões rodoviárias e ferroviárias, (i) qualificação no PPI.

\section{REFERÊNCIAS}

AMARAL, Antônio Carlos Cintra do. Concessão de serviço público: novas tendências. São Paulo: Quartier Latin, 2012.

AMORIM, João Pacheco de. O princípio da temporalidade dos contratos públicos: considerações sobre a duração máxima dos contratos e respetiva prorrogabilidade dentro e para lá desse limite temporal. In: GONÇALVES, Pedro Costa (Org.). Estudos de contratação pública. v. 4. Coimbra: Coimbra, 2013. p. 19-77.

ANDRADE, Letícia Queiroz de. Teoria das relações jurídicas da prestação de serviço público sob regime de concessão. São Paulo: Malheiros, 2015. 
ARAGÃO, Alexandre Santos de. Direito dos serviços públicos. 3. ed. Rio de Janeiro: Forense, 2013.

AZEVEDO, Eurico de Andrade; ALENCAR, Maria Lúcia Mazzei de. Concessão de serviços públicos: comentários às Leis 8.987 e 9.074 (Parte Geral), com as modificações introduzidas pela Lei 9.648, de 27.5.98. São Paulo: Malheiros, 1998.

BARCELLOS, Ana Paula de. A gestão do tempo pela regulação: parâmetros constitucionais para a prorrogação de prazos e alguns casos concretos. In: PEREIRA, Caio Mario da Silva; PINHEIRO, Luis Felipe Valerim. Direito da Infraestrutura. v. 2. São Paulo: Saraiva, 2017. p. $173-213$.

BARROSO, Luís Roberto. Alteração dos contratos de concessão rodoviária. In: OLIVEIRA, Farlei M. Riccio de (Coord.). Direito Administrativo Brasil - Argentina: estudos em homenagem a Agustín Gordillo. Belo Horizonte: Del Rey, 2007. p. 245-280.

BEZNOS, Clovis. Concessão de serviço público, prorrogação, vícios do edital de licitação. Revista de Direito Público, São Paulo, v. 24, n. 97, p. 263-271, jan./mar. 1991.

BORGES, Alice Gonzalez. Arrendamento de áreas portuárias, contrato de prorrogação, licitação, obrigatoriedade. Boletim de Direito Administrativo, São Paulo, v. 17, n. 11, p. 858 863, nov. 2001.

BRASIL. Superior Tribunal de Justiça. Acórdão de decisão que reconheceu a legitimidade da prorrogação por emergência. Agravo Regimental no Agravo em Recurso Especial no 481.094/RJ. Agravante: Linave Transportes Ltda. Agravado: Ministério Público do Estado do Rio de Janeiro. Relator: Ministro Mauro Campbell Marques. 21 de maio de 2014. Disponível em: $<$ https://ww2.stj.jus.br/websecstj/cgi/revista/REJ.cgi/ATC?seq $=35273953 \&$ tipo $=91 \&$ nreg $=20$ $1400429861 \&$ SeqCgrmaSessao $=\&$ CodOrgaoJgdr $=\& d t=20140521 \&$ formato $=P D F \&$ salvar $=$ false $>$. Acesso em: 2 ago. 2019.

BRASIL. Superior Tribunal de Justiça. Acórdão de decisão que reconheceu que a prorrogação por interesse público pressupõe outorga precedida de licitação pública, bem assim a não realização de prorrogação por interesse público anteriormente. Recurso Especial no 912.402/GO. Recorrente: Gerplan Gerenciamento ePlanejamento Ltda. Recorridos:Ministério Público do Estado deGoiáse Estado deGoiás. Relator:Ministro Mauro Campbell Marques.19deagosto de 2009. Disponível em: $<$ https://ww2.stj.jus.br/websecstj/cgi/revista $/$ REJ.cgi/ATC?seq $=5621759 \&$ tipo $=91 \& n$ reg $=200$ $700024535 \&$ SeqCgrmaSessao $=\&$ CodOrgaoJgdr $=\& d t=20090819 \&$ formato $=$ PDF \& salvar $=$ false $>$. Acesso em: 2 ago. 2019.

BRASIL. Supremo Tribunal Federal. Acórdão de decisão que reconheceu que a prorrogação por interesse público pressupõe consenso entre as partes. Recurso em Mandado de Segurança no 34.203/DF. Recorrente: Cemig Geração e Transmissão S/A. Recorrido: União Federal. Relator: Ministro Dias Toffoli. 19 de março de 2018. Disponível em: <http://redir.stf.jus.br/ paginadorpub/paginador.jsp?docTP=TP\&docID=14526265>. Acesso em: 2 ago. 2019. 
BRASIL. Supremo Tribunal Federal. Acórdão de decisão que reconheceu que a prorrogação por interesse público pressupõe outorga precedida de licitação pública. Agravo Regimental nos Embargos de Declaração no Recurso Extraordinário com Agravo no 869.0o7/DF. Agravante: Viação Paraíso Ltda. Agravados: Departamento de Transportes Rodoviários do Estado do Rio de Janeiro e Ministério Público do Estado do Rio de Janeiro. Relator: Ministro Dias Toffoli. 26 de maio de 2017. Disponível em: <http://redir.stf.jus.br/paginadorpub/paginador. jsp?docTP=TP\&docID=12955430 >. Acesso em 2 ago. 2019.

BRASIL. Tribunal de Contas da União. Acórdão de decisão que reconheceu a legitimidade da prorrogação por interesse público. Acórdão no 2.253/15. Interessados: Ministério de Minas e Energia e Agência Nacional de Energia Elétrica. Relator: Ministro José Múcio Monteiro. 9 de setembro de 2015. Disponível em: <https://pesquisa.apps.tcu.gov.br/\#/documento/acordaocompleto/*/NUMACORDAO\%253A2253\%2520ANOACORDAO\%253A2015\%2520RELA TOR\%253A\%2522JOS\%25C3\%2589\%2520MUCIO\%2520MONTEIRO\%2522\%2520COL EGIADO\%253A\%2522Plen\%25C3\%25A1rio\%2522/DTRELEVANCIA\%2odesc,\%2oNUM ACORDAOINT\%2odesc/o/\%2o?uuid=4do5456o-8azd-11e>. Acesso em: 2 ago. 2019.

BRASIL. Tribunal de Contas da União. Acórdão de decisão que reconheceu a legitimidade da prorrogação por interesse público, bem assim que tal espécie de prorrogação pressupõe a vantajosidade da medida. Acórdão no 2.20o/15. Interessadas: Secretaria dos Portos da Presidência da República e Agência Nacional de Transportes Aquaviários. Relatora: Ministra Ana Arraes. 2 de setembro de 2015. Disponível em: <https://pesquisa.apps.tcu.gov.br/\#/documento/ acordao-completo/*/NUMACORDAO\%253A2200\%2520ANOACORDAO\%253A2015/ DTRELEVA NCIA\%2odesc,\%2oNUMACORDAOINT\%2odesc/o/\%2o?uuid=3afa5850-afb411e9-994d-fd7od475765f>. Acesso em: 2 ago. 2019.

BRASIL. Tribunal de Contas da União. Acórdão de decisão que reconheceu que a prorrogação por interesse público pressupõe a não realização de prorrogação por interesse público anteriormente. Acórdão no 574/o6. Interessado: Ministério Público junto ao Tribunal de Contas. Entidade: Empresa Brasileira de Correios e Telégrafos. Relator: Lincoln Magalhães da Rocha (Conv.). 19 de abril de 2006. Disponível em: <https://pesquisa.apps.tcu.gov.br/\#/documento/ acordao-completo/*/NUMACORDAO\%253A574\%2520ANOACORDAO\%253A2006/ DTRELEVA NCIA\%2odesc,\%2oNUMACORDAOINT\%2odesc/o/\%2o?uuid=c845ao5o-dfbd11e9-95f1-d3be58ccdo55>. Acesso em: 2 ago. 2019.

BRASIL. Tribunal de Contas da União. Acórdão de decisão que reconheceu que a prorrogação por interesse público pressupõe o fiel cumprimento do contrato de concessão pela concessionária. Acórdão no 1.171/18. Interessada: Libra Terminais S/A. Entidades: Companhia Docas do Estado de São Paulo, Ministério dos Transportes, Portos e Aviação Civil e Agência Nacional de Transportes Aquaviários. Relatora: Ministra Ana Arraes. 23 de maio de 2018. Disponível em: <https://pesquisa.apps.tcu.gov.br/\#/documento/acordaocompleto/*/NUMACORDAO\%253A1171\%2520ANOACORDAO\%253A2018\%2520COLE GIADO\%253A\%2522Plen\%25C3\%25A1rio\%2522/DTRELEVANCIA\%2odesc,\%2oNUMA CORDAOINT\%2odesc/o/\%2o?uuid=49474b9o-deo6-11e9-af7d-799ced588129>. Acesso em: 2 ago. 2019. 
BRASIL. Tribunal de Contas da União. Acórdão de decisão que reconheceu a legitimidade da prorrogação por reequilíbrio. Acórdão no 774/16. Interessada: Secretaria dos Portos da Presidência da República. Relator: Ministro Walton Alencar Rodrigues. 6 de abril de 2016. Disponível em: <https://pesquisa.apps.tcu.gov.br/\#/documento/acordaocompleto/*/NUMACORDAO\%253A774\%2520ANOACORDAO\%253A2016\%2520RELAT OR\%253A\%2522WALTON\%2520ALENCAR\%2520RODRIGUES\%2522\%2520COLEGIA DO\%253A\%2522Plen\%25C3\%25A1rio\%2522/DTRELEVANCIA\%2odesc,\%2oNUMACO RDAOINT\%2odesc/o/\%2o?uuid=ed4bobao-8azc-11e9-910>. Acesso em: 2 ago. 2019.

BRASIL. Tribunal Regional Federal da 3. ํㅡ Região. Acórdão de decisão que reconheceu que a prorrogação por interesse público pressupõe concessão em vigor. Apelação/Reexame Necessário no oooo274-24.2004.4.03.6104/SP. Apelante: Armazéns Gerais Colômbia S/A. Apelada: União Federal. Relator: Juiz Federal Valdeci dos Santos (Conv.). 6 de julho de 2010. Disponível em: <http://web.trf3.jus.br/acordaos/Acordao/BuscarDocumentoGedpro/697528>. Acesso em: 2 ago. 2019.

CÂMARA, Jacintho Arruda. O prazo nos contratos públicos. In: PIETRO, Maria Sylvia Zanella di (Coord.). Tratado de Direito Administrativo: licitação e contratos administrativos. v. 6. São Paulo: Revista dos Tribunais, 2014. p. 339-353.

CANTO, Mariana Dall'Agnol; GUZELA, Rafaella Peçanha. Prorrogações contratuais em contratos de concessão. In: MOREIRA, Egon Bockmann (Coord.). Contratos administrativos, equilíbrio econômico-financeiro e a taxa interna de retorno: a lógica das concessões e parcerias público-privadas. 1. reimp. Belo Horizonte: Fórum, 2017. p. 207-221.

CLÈVE, Clèmerson Merlin. Lei municipal que regula a concessão do serviço público de transporte coletivo e exigência constitucional de prévia licitação pública. Revista dos Tribunais online, São Paulo, v. 2, p. 239-288, ago. 2012. Disponível em: <https:// www.revistadostribunais.com.br/maf/app/resultList/document? \&src=rl\&srguid=ioad 82d9aooooo16d4a81a378b91bfb8d\&docguid=Icd5752doe82d11e1b7ofo1000000000o\&hitgu id=Icd 5752 doe 82 d11e1b 7 ofo $10000000000 \& \operatorname{spos}=1 \&$ epos $=1 \& \mathrm{td}=70 \&$ context $=5 \& \mathrm{crumb}-$ action=append\&crumb-label=Documento\&isDocFG=true\&isFromMultiSumm=true \&startChunk=1\&endChunk=1\#noteDTR.2012.450427-n36>. Acesso em: 19 set. 2019.

CRETELLA JÚNIOR, José. Direito da concessionária à continuação do desempenho do serviço público. In: CRETELLA JÚNIOR, José. Direito Administrativo perante os tribunais. v. 2. Rio de Janeiro: Forense Universitária, 1996. cap. 9.

DALLARI, Adilson Abreu. Transporte coletivo: concessão de serviço público: impossibilidade de prorrogação. Revista de Direito Público, São Paulo, n. 88, p. 79-88, out./dez. 1988.

FAGUNDES, Miguel Seabra. O regime legal do rádio e da televisão em face da Constituição Federal. Revista de Direito Administrativo, Rio de Janeiro, v. 65, p. 49-63, jul./set. 1961.

FARIA, Edimur Ferreira de. Curso de Direito Administrativo positivo. 2. ed. rev. atual. e ampl. de acordo com a Emenda Constitucional n. 20/98 e a Medida Provisória n. 1.795/99. Belo Horizonte: Del Rey, 1999. 
FREITAS, Rafael Véras de. As prorrogações e a relicitação previstas na Lei n. 13.448/2017: um novo regime jurídico de negociação para os contratos de longo prazo. Revista de Direito Público da Economia, Belo Horizonte, v. 17, n. 59, p. 175-199, jul./set. 2017.

FREITAS, Rafael Véras de; RIBEIRO, Leonardo Coelho. O prazo como elemento da economia contratual das concessões: as espécies de "prorrogação". In: MOREIRA, Egon Bockmann (Coord.). Contratos administrativos, equilíbrio econômico-financeiro e a taxa interna de retorno: a lógica das concessões e parcerias público-privadas. 1. reimp. Belo Horizonte: Fórum, 2017. p. 283-300.

GARCIA, Flavio Amaral. As parcerias público-privadas: prazo e prorrogação. In: JUSTEN FILHO, Marçal; SCHWIND, Rafael Wallbach (Coord.). Parcerias público-privadas: reflexões sobre os 10 anos da Lei 11.079/2004. São Paulo: Revista dos Tribunais, 2015. p. 579-6o8.

GONÇALVES, Pedro. A concessão de serviços públicos: uma aplicação da técnica concessória. Coimbra: Almedina, 1999.

GUIMARÃES, Bernardo Strobel; GAGGIANO, Heloísa Conrado. O que mudou no direito das concessões com a aprovação da MP n. 752: perguntas e respostas. Revista de Direito Público da Economia, Belo Horizonte, v. 15, n. 58, p. 9-22, abr./jun. 2017.

GUIMARÃES, Bernardo Strobel. O prazo nas concessões e as normas que estipulam vigência máxima do vínculo: algumas inquietações. In: MOREIRA, Egon Bockmann (Coord.). Contratos administrativos, equilíbrio econômico-financeiro e a taxa interna de retorno: a lógica das concessões e parcerias público-privadas. 1. reimp. Belo Horizonte: Fórum, 2017. p. 47-59.

HOUAISS, Antônio; VILLAR, Mauro de Salles. Dicionário Houaiss de língua portuguesa. Rio de Janeiro: Objetiva, 2009.

JUSTEN FILHO, Marçal. A ampliação do prazo contratual em concessões de serviço público. Revista de Direito Administrativo Contemporâneo, São Paulo, v. 4, n. 23, p. 109-135, mar./ abr. 2016.

MARQUES NETO, Floriano de Azevedo. Concessões. Belo Horizonte: Fórum, 2015.

MARTINS, Ricardo Marcondes. Teoria das contrafações administrativas. A\&C - Revista de Direito Administrativo \& Constitucional, Belo Horizonte, v. 16, n. 64, p. 115-148, abr./jun. 2016.

MEIRELLES, Hely Lopes. Concessão de serviço público: prorrogação. In: MEIRELLES, Hely Lopes. Estudos e pareceres de Direito Público. v. 6. São Paulo: Revista dos Tribunais, 1982. p. $405-414$.

Licitação e contrato administrativo: de acordo com as Leis 8.666, de 21.6.1993, 8.883, de 8.6.1994, e 9.648, de 27.5.1998. Atual. por Eurico de Andrade Azevedo e Maria Lúcia Mazzei de Alencar. 13. ed. São Paulo: Malheiros, 2002. 
MELLO, Celso Antônio Bandeira de. Consulta da Associação Brasileira de Concessionárias de Rodovias - ABCR. In: CARVALHO, André Castro (Org.). Contratos de concessão de rodovias: artigos, decisões e pareceres jurídicos. São Paulo: MP, 2009. p. 51-65.

MELLO, Rafael Munhoz de. Prorrogação de concessão de serviço público. Revista de Direito Público da Economia, Belo Horizonte, v. 12, n. 46, p. 207-222, abr./jun. 2014.

MORAIS, Antão de. Serviço telefônico, expiração do prazo da concessão, fixação, fiscalização e revisão de tarifas, taxa de expansão do serviço. Revista de Direito Administrativo, Rio de Janeiro, v. 49, p. 445-464, jul./set. 1957.

MOREIRA NETO, Diogo de Figueiredo; FREITAS, Rafael Véras de. A nova regulação portuária. Belo Horizonte: Fórum, 2015.

NASCIMENTO, Carlos Fernando do. A prorrogação de contratos de concessão de infraestruturas de transporte terrestre em uma visão luso-brasileira. 2017. Artigo científico apresentado como requisito para aprovação na Disciplina Direito Administrativo (Mestrado em Direito e Ciência Jurídica). Faculdade de Direito, Universidade de Lisboa, Lisboa. 2017.

REALE, Miguel. Mutabilidade dos contratos administrativos. In: REALE, Miguel. Direito Administrativo: estudos e pareceres. Rio de Janeiro: Forense. 1969. p. 45-66.

ROCHA, Cármen Lúcia Antunes. Estudo sobre concessão e permissão de serviço público no Direito brasileiro. São Paulo: Saraiva, 1996.

RODRIGUES JUNIOR, Otavio Luiz. Da renovação das concessões e permissões de serviços de radiodifusão em face do arquivamento por órgão camerário do Congresso Nacional. Revista de Direito Privado, São Paulo, v. 6, n. 22, p. 241-249, abr./jun. 2005.

SAADI, Mário; SANTOS NETO, Raul Dias dos. Prorrogação antecipada de prazo de contratos de concessão. Revista de Direito Administrativo Contemporâneo, São Paulo, v. 4, n. 27, p. 79-107, nov./dez. 2016.

SANTOS, Rodrigo Valgas dos. Concessão de serviço público: a prorrogação do prazo de exploração para recomposição do equilíbrio econômico-financeiro do contrato. Revista Interesse Público, Porto Alegre, v. 8, n. 38, p. 85-111, jul./ago. 2006.

SCHWIND, Rafael Wallbach. Prorrogação dos contratos de arrendamento portuário. In: PEREIRA, Cesar; SCHWIND, Rafael Wallbach (Org.). Direito portuário brasileiro: Lei 12.815, porto organizado, poligonal, arrendamento e autorização, arbitragem. São Paulo: Marcial Pons, 2015 .

SOUTO, Marcos J. Villela. Direito Administrativo contratual. Rio de Janeiro: Lumen Juris, 2004 . 
SUNDFELD, Carlos Ari; CÂMARA, Jacintho Arruda. Uma crítica à tendência de uniformizar com princípios o regime dos contratos públicos. Revista de Direito Público da Economia, Belo Horizonte, v. 11, n. 41, p. 57-72, jan./mar. 2013.

TELLES, Antonio A. Queiroz. Introdução ao Direito Administrativo. 2. ed. rev. atual. e ampl. São Paulo: Revista dos Tribunais, 2000.

TORGAL, Lino. Prorrogação do prazo de concessões de obras e de serviços públicos. Revista de Contratos Públicos, Coimbra, n. 1, p. 219-263, jan./abr. 2011. 